\title{
Choking Affects the Operation Diagram of a CFB Riser
}

\author{
H. L. Zhang, ${ }^{1}$ J. Degrève, ${ }^{1}$ J. Baeyens, ${ }^{2}$ and R. Dewil ${ }^{3}$ \\ ${ }^{1}$ Department of Chemical Engineering, KU Leuven, De Croylaan 46, 3001 Heverlee, Belgium \\ ${ }^{2}$ School of Engineering, University of Warwick, Coventry CV4 7AL, UK \\ ${ }^{3}$ Process and Environmental Technology Laboratory, Department of Chemical Engineering, KU Leuven, \\ 2880 Sint-Katelijne-Waver, Belgium
}

Correspondence should be addressed to H. L. Zhang; huili.zhang@cit.kuleuven.be

Received 30 October 2013; Revised 26 December 2013; Accepted 10 January 2014; Published 4 March 2014

Academic Editor: Jürgen Tomas

Copyright $\odot 2014$ H. L. Zhang et al. This is an open access article distributed under the Creative Commons Attribution License, which permits unrestricted use, distribution, and reproduction in any medium, provided the original work is properly cited.

Experiments in 3 different CFB risers have confirmed that common riser operations can be hampered in a well-defined $(U, G)$ range where choking occurs. Geldart A-type powders were investigated. Experimental results of the choking velocity were empirically correlated, being about $30 \%$ lower than predicted by the correlation of $\mathrm{Bi}$ and $\mathrm{Fan}$, but largely exceeding other predictions. Introducing the findings into the operation diagram presented by Mahmoudi et al. adds a region where stable riser operation is impossible. The adapted diagram enables CFB designers to better delineate the operating characteristics.

\section{Introduction}

CFBs are widely used in the chemical, mineral, environmental, and energy process industries. Several authors stressed the need for a clear identification of the different operation regimes in the riser of a CFB, to ensure a better comprehension of the hydrodynamic context and thus correctly design the loop. First approaches to develop a "work map" of the riser operation were presented by, for example, Grace [1], Yerushalmi and Avidan [2], and Bai et al. [3]. It was further developed by Chan et al. [4] and Mahmoudi et al. $[5,6]$ for both Geldart A- and B-type powders: the operating gas velocity $(U)$ and the solids circulation flux $(G)$ jointly delineate different regimes, called, respectively, dilute riser flow (DRF), core-annulus flow (CAF) (possibly with a turbulent fluidized bed at the bottom of the riser (TFBB)), and dense riser upflow (DRU). For a given powder and its associated transport velocity, $U_{\mathrm{TR}}$, the combination of $U$ and $G$ will determine the flow regime encountered. Common riser operations can, however, be hampered in a specific $(U, G)$ range where choking occurs, being understood as the phenomenon where a small change in gas or solids flow rate prompts a significant change in the pressure drop and/or solids holdup: the stable riser upflow regime is no longer maintained when $G$ values exceed a certain limit for a low-tomoderate gas velocity. Considerable efforts have been made in probing choking in CFBs, and several empirical equations have been proposed, as summarized in the following.

Literature Correlations to Predict Choking Velocities, $U_{\mathrm{Ch}}$. The following equations were proposed.

Leung et al. [7]

$$
U_{\mathrm{Ch}}=32.3 \frac{G}{\rho_{p}}+0.97 U_{t}
$$

Matsen [8]

$$
U_{\mathrm{Ch}}=10.74 U_{t}\left(\frac{G}{\rho_{p}}\right)^{0.227} ;
$$

Yousfi and Gau [9]

$$
\frac{U_{\mathrm{Ch}}}{\sqrt{g d_{p}}}=32 \mathrm{Re}_{t}^{-0.06}\left(\frac{G}{\rho_{g} U_{\mathrm{Ch}}}\right)^{0.28} ;
$$

Bi and Fan $[10]$

$$
\frac{U_{\mathrm{Ch}}}{\sqrt{g d_{p}}}=21.6\left(\frac{G}{\rho_{g} U_{\mathrm{Ch}}}\right)^{0.542} \mathrm{Ar}^{0.105} \text {. }
$$


TABle 1: Powders used in the different rigs.

\begin{tabular}{lccccccc}
\hline Powder & $d_{p}(\mu \mathrm{m})$ & $\rho_{p}\left(\mathrm{~kg} / \mathrm{m}^{3}\right)$ & $90 \%$ range $(\mu \mathrm{m})$ & $\mathrm{Ar}$ & $U_{t}(\mathrm{~m} / \mathrm{s})$ & $U_{\mathrm{TR}}(\mathrm{m} / \mathrm{s})$ & Riser I.D. $(\mathrm{m})$ \\
\hline Rounded sand & 74 & 2260 & $45-90$ & 33 & 0.44 & 2.20 & 0.05 \\
Angular sand & 72 & 2660 & $35-95$ & 36 & 0.41 & 1.73 & 0.1 \\
Spent FCC & 70 & 1630 & $45-100$ & 20 & 0.24 & 1.69 & 0.1 \\
Rounded sand & 84 & 2260 & $35-110$ & 48 & 0.46 & 2.56 & 0.1 \\
Angular sand & 98 & 2660 & $60-130$ & 98 & 0.77 & 3.67 & 0.15 \\
\hline
\end{tabular}

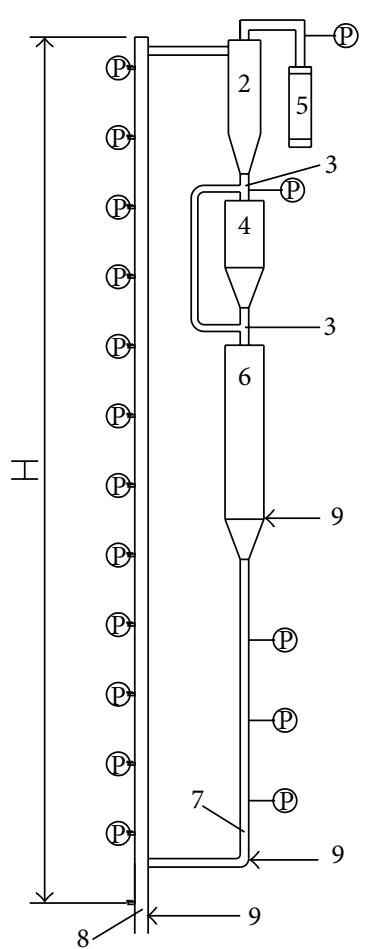

FIgure 1: The lab-scale CFBs with (1) riser; (2) cyclone; (3) diverter valve; (4) measuring bed; (5) bag filter; (6) slow bed; (7) L-valve; (8) metal gauge distributor; (9) air from roots blower; (P) pressure tapping.

The objective of the present research hence considered (i) the delineation of the choking phenomenon in different riser geometries and using different A-type powders, (ii) the comparison of experimental results with the empirical predictions of (1)-(4), and finally (iii) the adaptation of the proposed operation diagram of Mahmoudi et al. $[5,6]$ to include the $(U, G)$ region subject to choking.

\section{Materials and Methods}

The typical layout is illustrated in Figure 1, with essential dimensions given in the following.

Three risers, built in transparent polyethylene to enable a visual observation of the solids flow, were used: $0.05,0.1$, and $0.15 \mathrm{~m}$ I.D., with respective heights of $2.5,6.5$, and $6.5 \mathrm{~m}$. The exits of the risers are sharp $\left(90^{\circ}\right)$. The riser and all other parts of the CFB are electrically grounded. Filtered air from a compressor is fed both to the riser through a metal gauge distributor plate and to the recycle solids L-valve. The air velocities are determined from rotameter readings. The riser exit air passes a high efficiency Stairmand cyclone, followed by a fabric filter. Filter dust is periodically returned to the unit. The cyclone apex discharges the collected solids in the recycle loop, comprising a "slow" fluidized bed, and a bypass measuring bed. The slow bed, constructed as a fluidized bed with a diameter in excess of the other parts of the loop, creates the required pressure build-up to compensate the pressure drop of riser and cyclone: the slow bed has a diameter of $0.15 \mathrm{~m}$ (0.05 m I.D. riser) and $0.29 \mathrm{~m}$ I.D. for both other risers. The height of the slow bed (fluidized at $\sim 3 \times U_{\mathrm{mf}}$ ) is between 0.4 and $0.9 \mathrm{~m}$. The fluidizing air from the slow bed is vented to the fabric filter for dust removal. Solids from the cyclone discharge are periodically diverted for a given time to a measuring bed, where the solids circulation flux is measured from the collected volume (for a known $\Delta t$ ) and bulk density of solids. Measured solids are returned into the rig whilst being in operation. The L-valves have respective diameters of $0.025 \mathrm{~m}$ (small riser) and $0.05 \mathrm{~m}$ (both larger risers). The L-valve enters the column $\sim 10 \mathrm{~cm}$ above the distributor. Pressure tappings (provided with glass wool plug to prevent ingress of powder into the measuring lines) are installed every $0.5 \mathrm{~m}$ up the riser height. $\Delta P$ s were measured by both water manometers and by solid state pressure transducer in the 0.1 and $0.15 \mathrm{~m}$ I.D. rigs (with $A / D$ converter and PC logging). Pressure gradients along the height of the riser were measured. Powders used in the experiments are listed in Table 1, with corresponding relevant characteristics. Average particle sizes were measured by laser diffraction analysis (Malvern). 90\% of the particle size distribution was situated between the range specified in Table 1. Bulk and absolute densities were separately measured. The terminal velocity was calculated by the method established by Geldart [11]. The transport velocity, $U_{\mathrm{TR}}$, was calculated from Zhang [12]:

$$
U_{\mathrm{TR}}=\left(\frac{\mu_{\mathrm{air}}}{\rho_{\mathrm{air}} d_{p}}\right)(3.23+0.23 \mathrm{Ar}) .
$$

For a given solids flux, $G$, the gas flow was progressively and gradually reduced from $\sim 10 \mathrm{~m} / \mathrm{s}$. The initial increase in $\Delta P$ over the bottom section of the riser corresponds with forming a turbulent fluidized bed at the bottom of the riser (TFBB), however, with continued solids elutriation. At increased $G$ or reduced $U$, it is followed by the collapse of the solids into a slugging state, with its characteristic $\Delta P$ fluctuation frequency of $0.7-1 \mathrm{~Hz}$ [13]. A further decrease of 


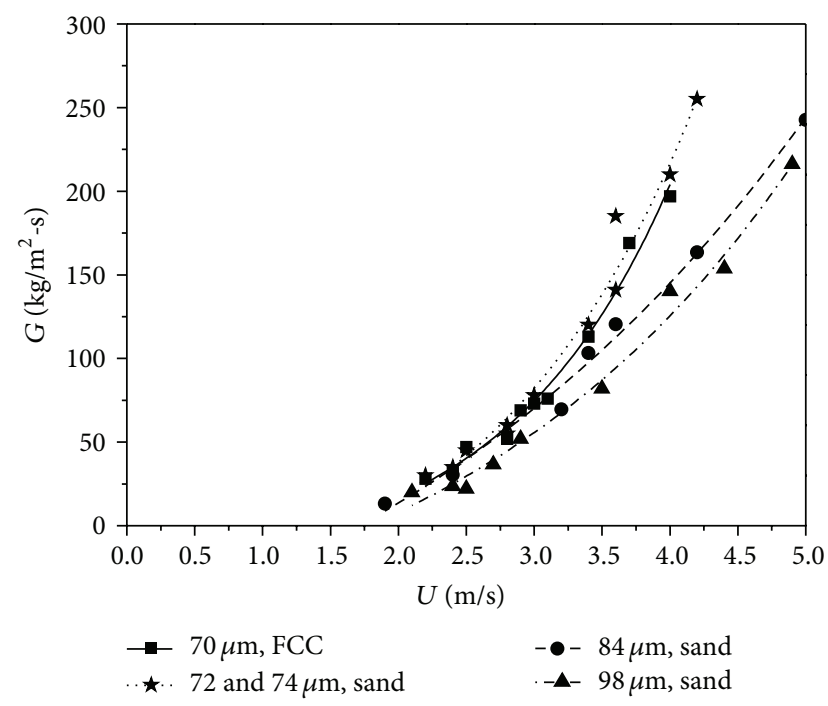

Figure 2: Experimental choking solids circulation flux, $G$, versus choking velocity $U_{\mathrm{Ch}}$ (left of data points: choking; right: stable circulating bed). Characteristics of powders and rigs used are given in Table 1 .

the gas velocity at the given $G$ leads to the formation of a fixed bed, without further upward solids transport. At the given $G$ value of slugging, the corresponding gas velocity was selected as choking velocity, $U_{\mathrm{Ch}}$, in the present study. Gas velocities were varied between 2 and $10 \mathrm{~m} / \mathrm{s}$, for solids circulation fluxes between 10 and $260 \mathrm{~kg} / \mathrm{m}^{2} \mathrm{~s}$.

\section{Results and Discussion}

Observed choking conditions are presented in Figure 2 with corresponding choking velocities, $U_{\mathrm{Ch}}$, at given solids circulation flux $(G)$. Characteristics of powders and the dimensions of the risers they were tested in are given in Table 1. Clearly, (i) the particle size has a significant influence at higher values of $G$; and (ii) the choking velocity increases when $G$ increases. No pronounced effect of the riser I.D. (0.05-0.10 I.D. for sand of $70-84 \mu \mathrm{m})$ was noticed.

The comparison of experimental data and literature predictions (1)-(4) is illustrated in Figure 3 for the $84 \mu \mathrm{m}$ rounded sand. For all powders, Leung et al. [7] and Matsen [8] underestimate $U_{\mathrm{Ch}}$. The Yousfi and Gau [9] prediction is fair at lower $U$ and/or $G$ values. This is also the case when using the Bi and Fan [10] equation: a fair prediction at low $U$ and/or $G$ is followed by an overestimation at increasing $U$ values velocity, although the trend of the predictions is fairly parallel with the experimental measurements. This parallelism was further investigated in Figure 4 for all powders.

In view of the overestimation by (4), especially at $U \geq$ $2 \mathrm{~m} / \mathrm{s}$, experimental results were correlated with a slightly modified $\mathrm{Bi}$ and Fan equation, the only difference being the empirical coefficient: 14.6 in the case of the present study

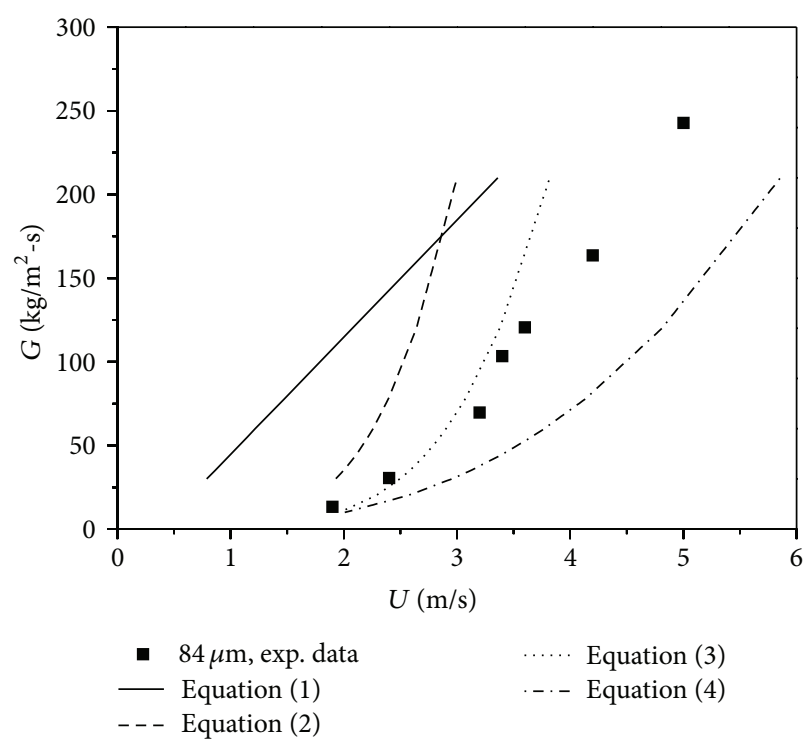

FIGURE 3: Illustration of the comparison of experimental data for $84 \mu \mathrm{m}$ rounded sand, with predictions by different literature equations (1)-(4).

against 21.6 in the original equation. The resulting equation is given as

$$
\frac{U_{\mathrm{Ch}}}{\sqrt{g d_{p}}}=14.6\left(\frac{G}{\rho_{g} U_{\mathrm{Ch}}}\right)^{0.542} \cdot \mathrm{Ar}^{0.105}
$$

The comparison of all experimental data, with (6), is illustrated in Figure 5(a).

The literature data on choking conditions are scarce outside the experimental data that lead to the establishment of the empirical equations of (1)-(4). Additional data were extracted from graphs given in papers by Du and Fan [14], Du et al. [15], and Bai et al. [16]. A comparison of the extracted data and the prediction of (6) is illustrated in Figure 5(b). The prediction is seen to be fair, even beyond the range of our experimental $G$ values.

Having established a correlation for $U_{\mathrm{Ch}}$ in terms of gas and solids properties, the "work" diagram of Mahmoudi et al. $[5,6]$ can be adapted, as illustrated in Figure 6. Clearly, the occurring choking regime is specifically important at high values of $G$ and/or low values of $\left(U-U_{\mathrm{TR}}\right)$. An inaccuracy of $0.2 \mathrm{~m} / \mathrm{s}$ was indicated with respect to $U_{\mathrm{TR}}$ predictions from (5).

Both $U_{\mathrm{TR}}$ and the delineation curve separating zone $I_{B}$ from zone $\mathrm{V}$ should be calculated for the specific particlegas system under scrutiny. For Zone V (DRU) operation, $U$ values commonly exceed $10 \mathrm{~m} / \mathrm{s}$ with $G$ values in excess of $800 \mathrm{~kg} / \mathrm{m}^{2}$ s. This operation is certainly beyond the $U, G$ region where choking is likely to occur. Choking should be considered in the transition regime between Zones IV and V whenever lower excess gas velocities are selected. 


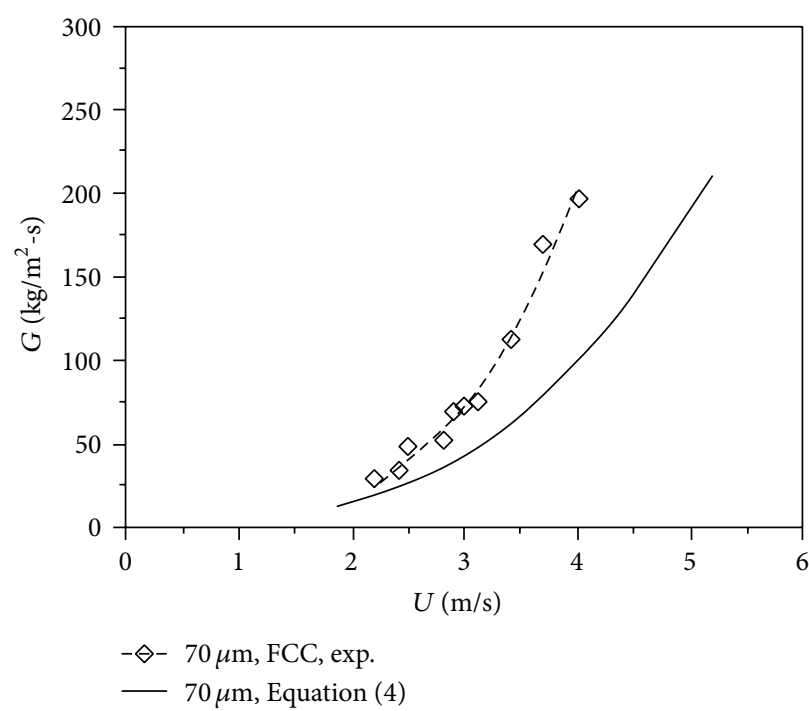

(a)

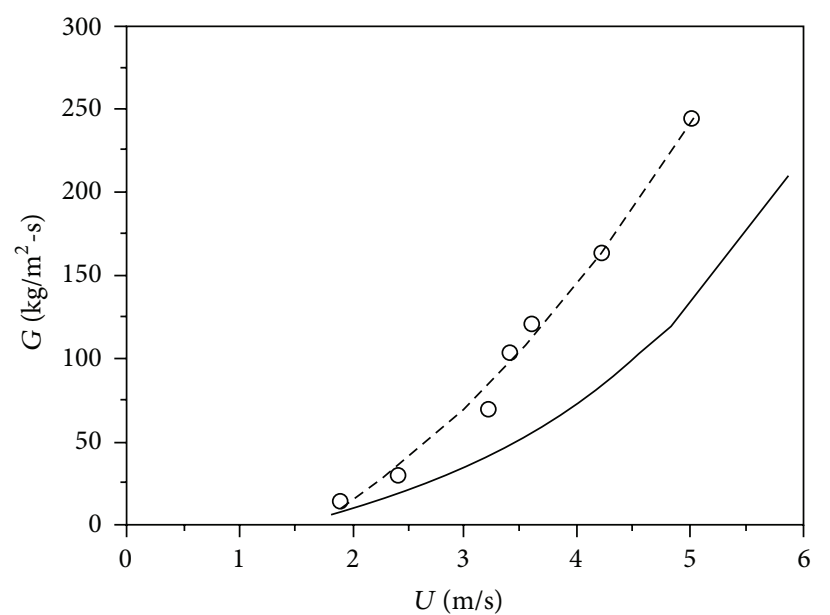

$-\Theta-84 \mu \mathrm{m}$, sand, exp.

- $84 \mu \mathrm{m}$, Equation (4)

(c)

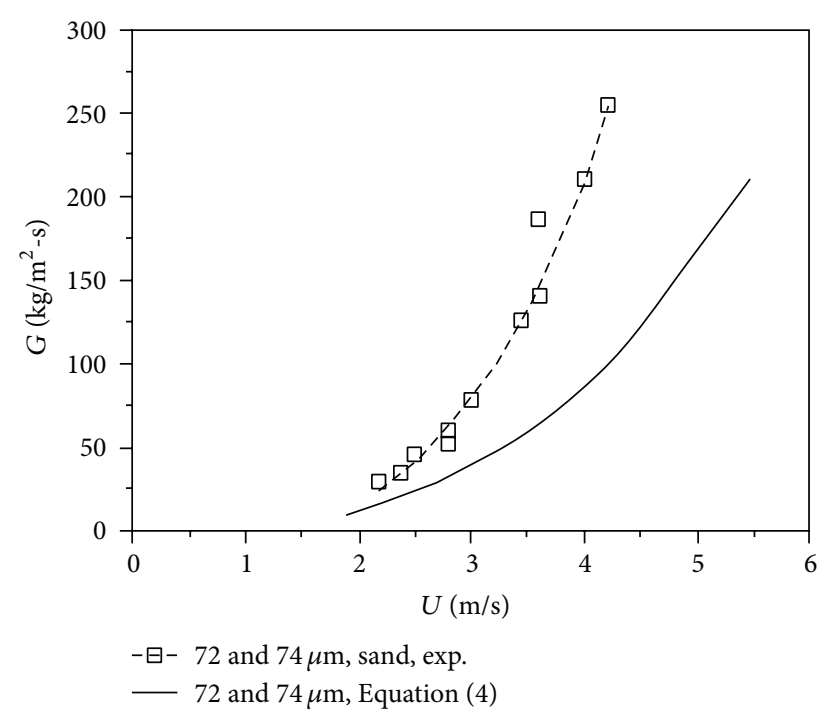

(b)

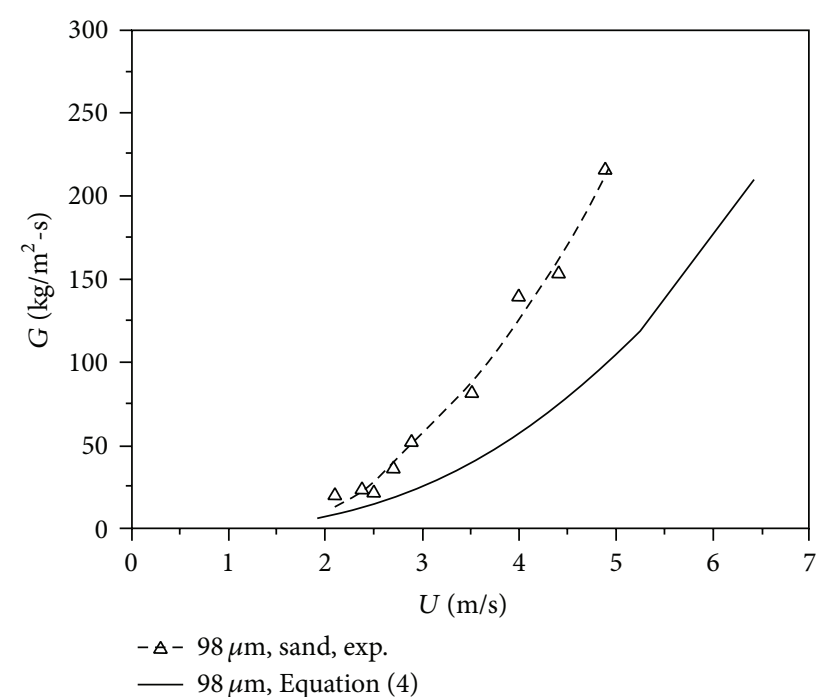

(d)

FIGURE 4: Comparison of (4)-predicted $\left(G_{\mathrm{Ch}}-U_{\mathrm{Ch}}\right)$ values with experimental data.

The resulting operation diagram of a CFB riser better delineates operating characteristics. Choking does not affect the CAF operation mode but delays a stable DRU mode to higher velocities than predicted by $U_{\mathrm{TR}}$. The use of equations from (1) to (4) will either overpredict (4) or underestimate (1)-(3) the excess gas velocity needed to avoid choking.

\section{Conclusions}

The choking velocity was measured for different powders in different riser geometries. Equation (6) predicts $U_{\mathrm{Ch}}$ for a specific gas-solid system. The existence of a distinct choking region in the operation of the riser implies that a previously presented operation diagram is extended with an additional region, especially at low values of $\left(U-U_{\mathrm{TR}}\right)$ and higher values of $G$, where choking will prevent a stable riser operation.

\section{Abbreviations}

Ar: $\quad$ Archimedes number, $\left[d_{p}^{3}\left(\rho_{p}-\rho_{g}\right) \rho_{g} g / \mu_{g}^{2}\right][-]$

$G$ : $\quad$ Solids circulation flux, $\left[\mathrm{kg} / \mathrm{m}^{2} \mathrm{~s}\right]$

$d_{p}: \quad$ Average particle size of the powder, [m]

$\Delta P: \quad$ Pressure drop in the riser, $[\mathrm{Pa}]$

$t: \quad$ Time, $[\mathrm{s}]$

$U: \quad$ Superficial gas velocity in the riser, $[\mathrm{m} / \mathrm{s}]$

$U_{\mathrm{mf}}, U_{t}$ : Minimum fluidization velocity and terminal particle velocity, respectively, $[\mathrm{m} / \mathrm{s}]$

$U_{\mathrm{TR}}:$ Transport velocity (onset of fast fluidization) $[\mathrm{m} / \mathrm{s}]$

$U_{\mathrm{Ch}}: \quad$ Choking velocity, $[\mathrm{m} / \mathrm{s}]$

$\rho_{p}: \quad$ Absolute particle density, $\left[\mathrm{kg} / \mathrm{m}^{3}\right]$

$\rho_{g}: \quad$ Density of gas, $\left[\mathrm{kg} / \mathrm{m}^{3}\right]$

$g: \quad$ Gravitational acceleration, $\left[\mathrm{m} / \mathrm{s}^{2}\right]$

$\mu_{g}: \quad$ Viscosity of gas $[\mathrm{kg} / \mathrm{ms}]$. 


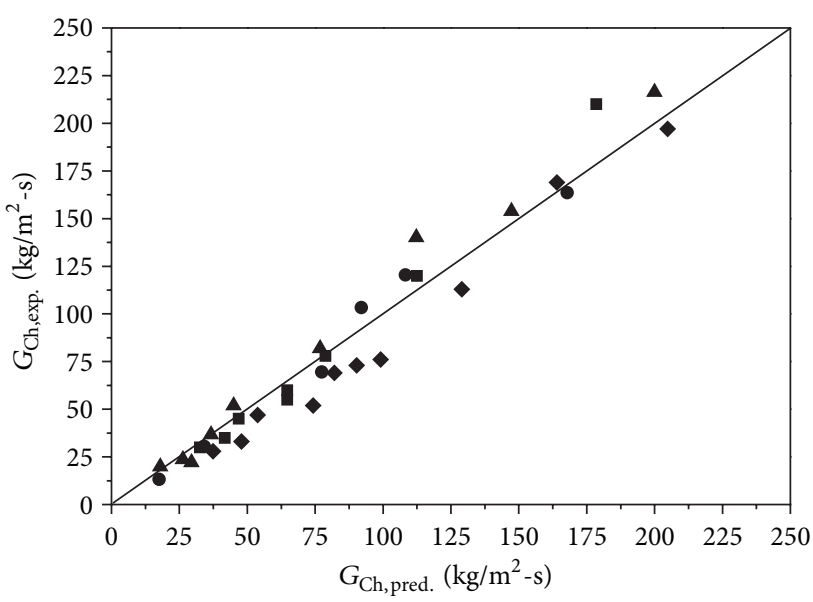

(a)

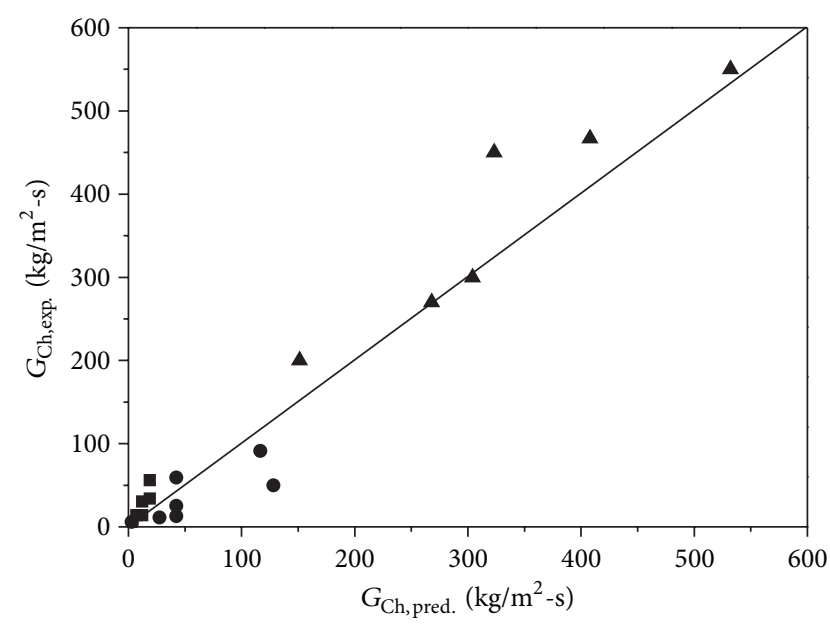

(b)

Figure 5: (a) Comparison of (6)-predicted $G_{\text {Ch,pre. }}$ values with experimental data $G_{\text {Ch,exp. }}$ for (a) $70 \mu \mathrm{m}$ FCC; (b) 72 and $74 \mu \mathrm{m}$ sand; (c)

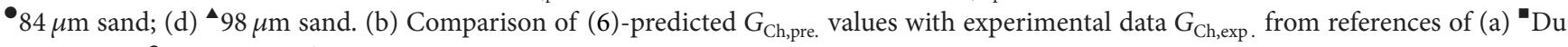
and Fan; (b) ${ }^{\bullet}$ Du et al.; (c) ${ }^{\wedge}$ Bai et al.

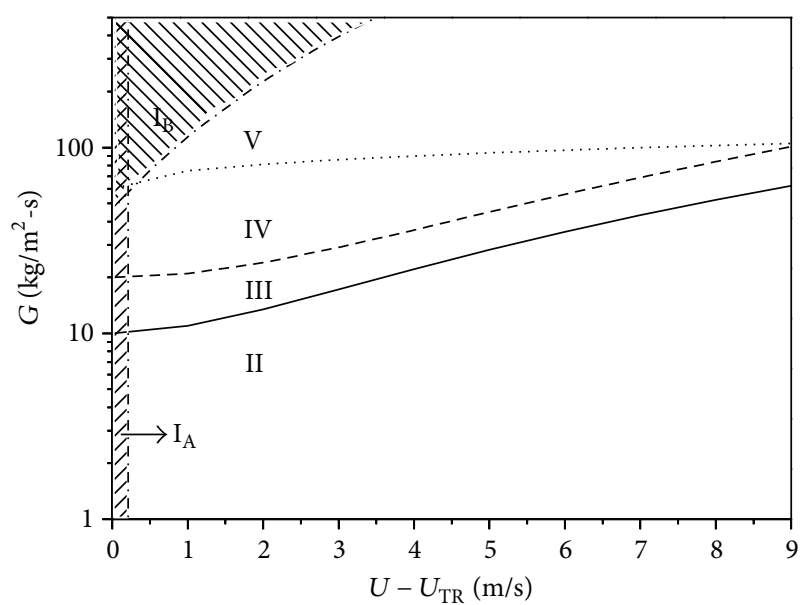

FIGURE 6: Operation of a CFB riser as $G$ versus $U-U_{\text {TR }}$ (adapted from Mahmoudi et al. $[5,6])$. Zone $I_{A}$ : Zone I: transition zone and/or inaccuracy in $U_{\mathrm{TR}}$ prediction; Zone $I_{B}$ : zone of choking; Zone II: dilute riser flow (DRF); Zone III: core-annulus flow (CAF) only; Zone IV: CAF with turbulent fluidized bed at the bottom (TFBB) of the riser; Zone V: dense riser upflow (DRU). - : transition DRFCAF: $G=10+\left(U-U_{\mathrm{TR}}\right)^{1.8},-\cdots-$ - transition CAF-CAF with TFBB: $G=20+\left(U-U_{\mathrm{TR}}\right)^{2}$, ........: transition CAF with TFBB-DRU: $G=60+15\left(U-U_{\mathrm{TR}}\right)^{0.5}$, and -.-.-.-: $84 \mu \mathrm{m}$ sand: (6) predicted.

\section{Conflict of Interests}

The authors declare that there is no conflict of interests regarding the publication of this paper.

\section{References}

[1] J. R. Grace, "High-velocity fluidized bed reactors," Chemical Engineering Science, vol. 45, no. 8, pp. 1953-1966, 1990.

[2] J. Yerushalmi and A. Avidan, "High velocity fluidization," in Fluidization, J. F. Davidson, R. Clift, and D. Harrison, Eds., pp.
225-289, Academic Press, New York, NY, USA, 2nd edition, 1985.

[3] D. Bai, E. Shibuya, Y. Masuda, K. Nishio, N. Nakagawa, and K. Kato, "Distinction between upward and downward flows in circulating fluidized beds," Powder Technology, vol. 84, no. 1, pp. 75-81, 1995.

[4] C. W. Chan, J. P. K. Seville, D. J. Parker, and J. Baeyens, "Particle velocities and their residence time distribution in the riser of a CFB," Powder Technology, vol. 203, no. 2, pp. 187-197, 2010.

[5] S. Mahmoudi, J. Baeyens, and J. Seville, "The solids flow in the CFB-riser quantified by single radioactive particle tracking," Powder Technology, vol. 211, no. 1, pp. 135-143, 2011.

[6] S. Mahmoudi, C. W. Chan, A. Brems, J. Seville, and J. Baeyens, "Solids flow diagram of a CFB riser using Geldart B-type powders," Particuology, vol. 10, no. 1, pp. 51-61, 2012.

[7] L. S. Leung, R. J. Wiles, and D. J. Nicklin, "Correlation for predicting choking flowrates in vertical pneumatic conveying," Industrial and Engineering Chemistry Process Design and Development, vol. 10, no. 2, pp. 183-189, 1971.

[8] J. M. Matsen, "Mechanisms of choking and entrainment," Powder Technology, vol. 32, no. 1, pp. 21-33, 1982.

[9] Y. Yousfi and G. Gau, "Aerodynamique de l'ecoulement vertical de suspensions concentrees gaz-solides-I. Regimes d'ecoulement et stabilite aerodynamique," Chemical Engineering Science, vol. 29, no. 9, pp. 1939-1946, 1974.

[10] H. T. Bi and L. S. Fan, "Regime transitions in gas-solid circulating fluidized beds," in Proceedings of the AIChE Annual Meeting, pp. 17-22, AIChE, Los Angeles, Calif, USA, 1991.

[11] D. Geldart, "Particle entrainment and carry-over," in Gas Fluidization Technology, D. Geldart, Ed., pp. 123-153, John Wiley \& Sons, New York, NY, USA, 1986.

[12] H. L. Zhang, Powder circulation systems for heat storage [Ph.D. thesis], KU Leuven, 2013.

[13] J. Baeyens and D. Geldart, "An investigation into slugging fluidized beds," Chemical Engineering Science, vol. 29, no. 1, pp. 255-265, 1974.

[14] B. Du and L. S. Fan, "Characteristics of choking behavior in circulating fluidized beds for group B particles," Industrial and 
Engineering Chemistry Research, vol. 43, no. 18, pp. 5507-5520, 2004.

[15] B. Du, W. Warsito, and L. Fan, "Imaging the choking transition in gas-solid risers using electrical capacitance tomography," Industrial and Engineering Chemistry Research, vol. 45, no. 15, pp. 5384-5395, 2006.

[16] D. Bai, A. S. Issangya, and J. R. Grace, "A novel method for determination of choking velocities," Powder Technology, vol. 97, no. 1, pp. 59-62, 1998. 

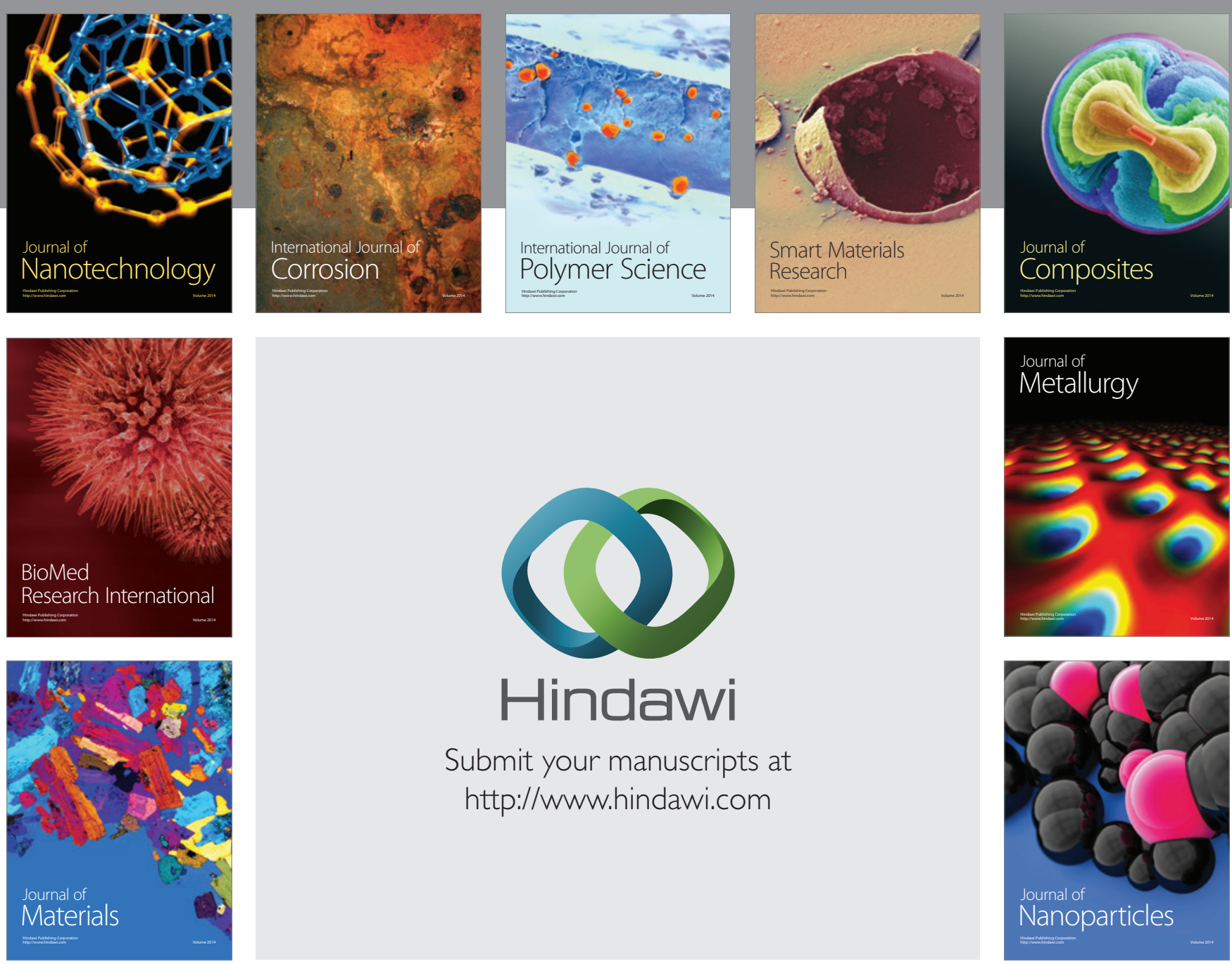

Submit your manuscripts at http://www.hindawi.com
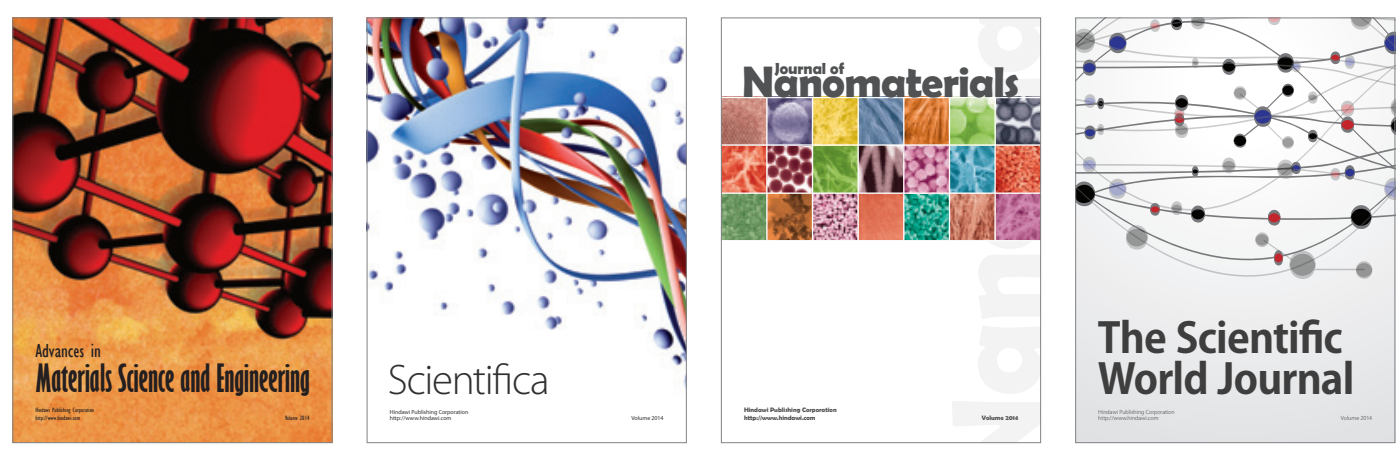

\section{The Scientific World Journal}
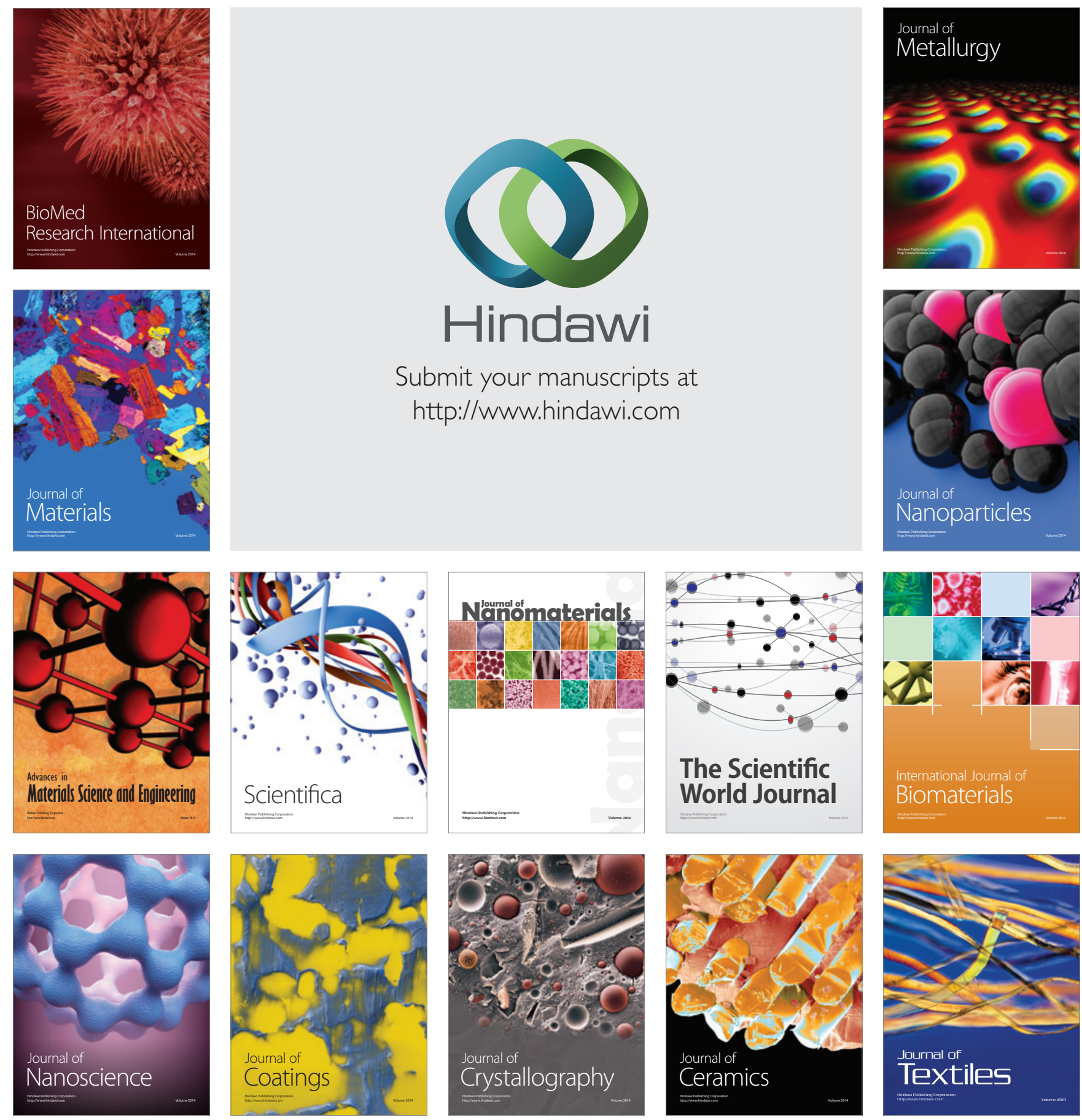